This item was submitted to Loughborough's Research Repository by the author.

Items in Figshare are protected by copyright, with all rights reserved, unless otherwise indicated.

\title{
A preliminary study on the role of simulation models in generating insights
}

\section{PLEASE CITE THE PUBLISHED VERSION}

http://dx.doi.org/10.1109/WSC.2014.7020191

\section{PUBLISHER}

(c) IEEE

\section{VERSION}

AM (Accepted Manuscript)

\section{PUBLISHER STATEMENT}

This work is made available according to the conditions of the Creative Commons Attribution-NonCommercialNoDerivatives 4.0 International (CC BY-NC-ND 4.0) licence. Full details of this licence are available at: https://creativecommons.org/licenses/by-nc-nd/4.0/

\section{LICENCE}

CC BY-NC-ND 4.0

\section{REPOSITORY RECORD}

Gogi, Anastasia, Antuela A. Tako, and Stewart Robinson. 2019. "A Preliminary Study on the Role of Simulation Models in Generating Insights". figshare. https://hdl.handle.net/2134/16720. 


\title{
A PRELIMINARY STUDY ON THE ROLE OF SIMULATION MODELS IN GENERATING INSIGHTS
}

\author{
Anastasia Gogi \\ Antuela A. Tako \\ Stewart Robinson \\ School of Business and Economics \\ Loughborough University \\ Loughborough, LE11 3TU, UK
}

\begin{abstract}
The generation of insight from simulation models has received little attention in the discrete-event simulation (DES) literature. Often DES studies claim to have supported problem understanding and problem solving by creating new and effective ideas, however little empirical evidence exists to support these statements. This paper presents the design of an experimental study which aims to understand the role of simulation models in generating insights. Study participants are asked to solve a task based on a problem of a telephone service for non-emergency health care. One independent variable is manipulated: the features of the simulation model, forming three conditions. Participants either use the animation or only the statistical results of the model or no model at all to solve the task. The paper provides a preliminary analysis of the pilot tests, which indicates that simulation models may assist users in gaining better understanding and in achieving divergent thinking.
\end{abstract}

\section{INTRODUCTION}

The discrete-event simulation (DES) community has seen major advancements since the introduction of Visual Interactive Modelling and Simulation (VIM\&S) features in almost all simulation software packages (Bell and O'Keefe 1987, Bell 1991). The introduction of VIM\&S provides simulation modelers with the opportunity to take a softer Operational Research (OR) approach, called the 'design-and-invent' paradigm (Ackoff 1969) when carrying simulation studies. In this alternative paradigm, models are conceived as a means that aid understanding about how a system currently operates and obtaining new ideas about 're-designing' that system in order to improve its operations in the future (Ackoff 1969). In a comparison of the characteristics of simulation modelling approaches, and in particular discrete-event simulation and system dynamics, DES is deemed better in making knowledge available than in creating knowledge (Bayer et al. 2010). In this paper we are interested in the knowledge created, and more specifically the insights generated as a result of using DES models.

In the creative cognitive psychology literature, the process of generating creative ideas, especially by intuition, which in turn can help address problems more effectively, is called insight (Schooler, Fallshore, and Fiore 1995). More specifically, insight is defined as "the cognitive process by which a problem solver suddenly moves from a state of not knowing how to solve a problem to a state of knowing how to solve a problem" (Mayer 2010, 276).

Both practitioners and academics report that DES models are used to support decision-making. However, the literature has limited examples reporting how the use of DES can generate insights (Robinson 2001; Monks, Robinson, and Kotiadis 2014). Even if insights are gained as a result of a DES intervention, it is usually beyond the scope of the project to identify whether insights are generated as a result of the human-to-model interaction or as a result of factors other than the simulation model. 
Anecdotal evidence shows that the creation of knowledge may sometimes be based on intuition rather than relying on systematical analysis of alternatives (Robinson 2001). We design a study, which aims to provide empirical evidence that the use of simulation models, and more specifically DES, promotes insights. This in turn, can help in providing a common basis of understanding under which conditions insights emerge. Therefore, this research benefits practitioners and academics in gaining an understanding of the value that simulation models have in decision making.

This paper presents the design of an experimental study that explores the extent to which features of VIM\&S, such as animation and statistical outcomes of a simulation model, contribute to insight generation. Our proposition is that the use of a DES model leads to insight generation. Participants, undergraduate students, are placed in three separate groups and given a task to solve. The task is based around a real-life problem, that of the UK's NHS111 service; a new telephone service for non-emergency health care. Participants are asked to solve the task either by using the animation or only the statistical results of the model or no model at all. Performance is measured based on whether insight occurs and the time taken to achieve insight. In this paper, we present the preliminary results of the pilot study carried out, while the results of the full study will be considered in future research.

The paper is organized as follows. Section two explores academic literature referring to the value of simulation in insight generation. Next, the full experimental study is described, explaining the hypothesis to be tested, the methodology, the participants involved, the procedure and the materials used. Section four provides the results of the pilot study, followed by conclusions.

\section{THE PROCESS OF INSIGHT GENERATION AND SIMULATION}

In this section we explore the process of insight generation and its value in simulation modelling. The first part of this section discusses whether academic literature provides enough evidence to recognize the role of simulation in insight generation. Then, the concept of 'insight' from other relevant fields is introduced in order to better understand how it might be brought in the simulation context.

\subsection{Empirical Evidence of Generating Insight from the Use of Simulation}

DES is generally viewed as a 'hard' OR technique. Although Robinson (2005) warns that alternative uses of DES are crucial for the future of the technique, van der Zee and Slomp $(2009,17)$ are surprised by seeing: "how the dominant view on simulation use, as described in many course books and implemented in software, has hardly altered since then. It still considers the use of simulation as just a methodology to analyse design decisions". On the other hand, practitioners and scholars often discuss that DES interventions help stakeholders to gain insights about their problems and subsequently to generate effective ideas on how to address them. However, such learning outcomes remain anecdotal evidence and they are often omitted from written case studies. Paul and Kuljis (2010) arrive to the same conclusion by claiming that the simulation community places more emphasis on model solving rather than problem solving. As a result, it is hard to find cases in the literature in which DES models were 'generators' of new and effective ideas.

A number of examples can be found in the literature that demonstrate the alternative use of DES such as Robinson (2001), Dobson and Shumsky (2006), Monks, Robinson and Kotiadis (2014), van der Zee and Slomp (2009), Smith (1990) and Elder (1992). Although these authors illustrate that DES can be used for 'softer' applications, their focus is mainly on problem understanding rather than creating new ideas to address problems. Robinson (2001) demonstrates that a softer approach can lead to both a better understanding of the problem situation and the creation of new and effective ideas during the intervention. However, the specific role of the simulation model in the generation of new and effective ideas is not made transparent. Although the author makes clear that the simulation model was the catalyst for problem understanding, it is not clear whether the ideas that were generated were the product of the human-tohuman and/or the human-to-model interaction. In the experimental study by Monks, Robinson and Kotiadis (2014), participants used simulation to improve the performance of a fictional Accident and Emergency (A\&E) department. However, few study participants managed to create new types of 
scenarios. Even though the study provides some evidence of insight generation, the contribution of the DES model in the creation of new ideas is not clear, because the participants were involved in the modelling process. Even if it is assumed that insights were generated due to the use of the DES model, the extent to which the animation and/or statistical features supported participants in insight generation is not considered.

While the DES literature does not provide much evidence on the alternative uses of the simulation model, the SD field has a well-developed philosophy of practice which intertwines simulation with learning (Sterman 1994, Morecroft 1992). However, learning from simulation models appears more challenging than expected. Recent experimental studies show that simulation users appear unable to explain or intuitively predict the behavior even of the simplest system. Scientists explain that people face this difficulty because they tend to misperceive dynamic rules and simplify the way a complex system is structured (Cronin, Gonzalez, and Sterman 2009; Langley and Morecroft 2004; Sterman 1989; Warren and Langley 1999). These empirical results are in alignment with behavioral decision theory which reveals that people suffer from bounded rationality because of a number of judgmental biases and heuristics that people employ in complex situations (Kahneman 2011). Even if simulation users consciously understand how and why a system behaves in a particular way, experimental findings show that this knowledge does not necessarily lead them to the creation of new strategies which improve the behavior of that system (Bakken, Gould, and Kim 1992).

The general conclusion that emerges from the above is that little empirical evidence exists to identify the role of a simulation model in supporting people create new and effective ideas. Furthermore, little attention has been paid to assessing the impact of animation and statistical features of simulation on insight generation. Next, the concept of insight is explored to then consider how it might be brought in the simulation context.

\subsection{The Concept of Insight}

The word 'Insight' is used in two ways. It is used as a state of understanding - that is, to gain insight into something (Smith 1995). Insight is also described as an experience, an Aha! experience, involving a moment of epiphany (Schooler, Fallshore, and Fiore 1995). This view is originally encountered in the story of Archimedes of Syracuse when he discovered the principle of displacement - 'eureka'. For this research we adopt this latter concept, proposing it as an alternative approach to measure the value of simulation as a means for creating knowledge.

To explore Aha! insight in more depth, relevant literature is considered and in particular, the theoretical domain of Gestalt theory (Maier 1940, Mayer 2010), creative cognitive psychology (Sternberg 2009) and a loose collection of studies on insight that have attempted to conceptualize the phenomenon (Metcalfe and Wiebe 1987, Kounios and Beeman 2009). Despite the fact that these streams of literature do not share the same theoretical foundation, it seems that they all agree upon the phenomenological perspective of the concept. Hence a satisfactory solution to the problem suddenly emerges after initial attempts to solve it have failed (i.e. impasse). This productive activity is about creating something new or novel. This affectively informed act of creativity is typically characterized by an Aha! experience.

Social scientists have offered many explanations about the mental mechanisms of insight generation, which seem somewhat interrelated. In short, in achieving illumination, a problem solver may overcome mental constraints (Weisberg 1995), change mental representations, become aware of a new association between parts of a system, change the meaning of some problem element or assimilate possible solutions from the environment (Davidson 1995). In other words, it is believed that prior knowledge and experience constrain people's worldview, and, as a result, this knowledge may prevent them from seeing the world as it really is. Nevertheless, by using past experience as a building block, avoiding being confined by habits or irrelevant associations, the problem solver may eventually identify the appropriate way to solve a problem; and hence insights emerge. 


\subsection{Insight in the Simulation Context}

Applying the above in the context of DES, it can be claimed that insight occurs when a simulation user suddenly knows how to improve the performance of a system after several failed alternative attempts in order to identify an improvement with a simulation model (i.e. what-ifs scenarios). The strategy used to achieve major improvements in the system involves doing something new or novel.

Decomposing the process of insight generation into its components allows us to operationalize the phenomenon. For instance, we can identify that insight occurs during the experimentation phase of a simulation project if the users go through the following problem solving pattern:

- an impasse - failed initial attempts to improve model performance

- a sudden generation of new or novel ideas on how a model can be improved

- the confirmation that these ideas lead to major improvements to a problem situation, or otherwise to its solution

Note that since a simulation model can only be a simplification of the real world, insights first concern the model and second, in a broader sense, the real-life system.

Bringing the possible causes of experiencing insights from the creative cognitive psychology literature to the context of DES, the following provides a non-exhaustive list of possible explanations for the occurrence of insight from the use of a simulation model. An epiphany may emerge after a simulation user:

- overcomes implicitly posed constraints - for instance, in Robinson (2001) the stakeholders realize that there was no actual need for hiring lower skilled staff to work on the helpline.

- changes the meaning of some problem element - for example, in Monks, Robinson and Kotiadis (2014) some participants succeed in ceasing a common misconception about the relationship between resource utilization and service level.

- assimilates possible solutions from the environment - in Bakken, Gould and Kim (1992), for instance, some participants manage to apply insights learned from the first game to the second one.

In this study, we consider both implicitly posed constraints and misconception of some problem elements in order to study the value of simulation in generating insights.

\section{STUDY DESIGN}

This section describes the aims and the design of the experimental study.

\subsection{Project Scope}

This paper is part of a $\mathrm{PhD}$ research project that aims to provide empirical evidence that simulation models, and specifically DES models, support users in generating insights. Our aim is to establish which features of VIM\&S, such as animation and statistical outcomes of a simulation model, contribute to insight generation. More specifically, the study objectives consists of the following:

Objective 1: To determine whether the use of a DES model supports users in generating insights.

Objective 2: To establish how the animation and statistical features of VIM\&S contribute to insight generation.

In order to address the research objectives above, the following hypotheses based on the literature discussed in section 2 and on general statements found in literature are examined: 
Hypothesis 1: Insights will be generated more frequently when a simulation model is used.

Hypothesis 2: The contribution of animation to the process of insight generation will differ from the contribution of statistical outcomes.

The first hypothesis examines the different rates of success on an insight problem between people who use a simulation model and those that do not. The problem is considered 'insightful' because it is designed in such a way that in order to be solved it requires participants to re-consider associations between elements of the problem and also to overcome implicitly posed biases and constraints. Success is determined based on participants' submitted answers to the task.

The second hypothesis considers whether people who are exposed either to animation or statistical outcomes of the simulation model demonstrate different rates of success. Success is defined in terms of the time and the total number of scenarios a participant employs to solve the problem as well as the types of scenarios considered.

\subsection{Methodology}

A controlled laboratory experiment is used to meet the objectives of this study (Section 3.1). Compared to methodologies such as observations and interviews, an experiment is considered beneficial because it allows the isolation and the determination of the features of VIM\&S that promote insights. Also compared to observing real life studies, it enables using a larger sample size, because the experiment can be replicated (Sternberg 2009).

A between-groups design is used and one independent variable is manipulated: the features of simulation model. In particular, the independent variable takes two levels: use of animation of the simulation (condition 1) or use of statistical results generated from simulation runs (condition 2). The experimental conditions are compared with a control condition - no use of a simulation model (Table 1).

Table 1: Levels of independent variable.

\begin{tabular}{|c|c|c|}
\hline Condition & Level & Features of simulation model \\
\hline \multirow{2}{*}{ Experimental } & 1 & Animation \\
\cline { 2 - 3 } & 2 & Statistical results \\
\hline Control & - & No simulation model \\
\hline
\end{tabular}

The difference between the two levels of the independent variable tests the extent to which the specific feature of simulation contributes to the generation of insights. Participants in condition one solve the problem by watching an animation of the simulation model. Participants in condition two solve the same problem by consulting the statistical outcomes generated from simulation runs. The control group is given the same amount of time and asked to solve the same problem, but no simulation model is provided. We compare the difference in performance between the control and experimental conditions to test for the benefit of using a simulation model to generate insights.

Insight is measured using two dependent variables. The first variable is the time taken to solve the problem. This is measured by recording the time that each participant takes to set up every scenario. The second variable is the change in participants' attitudes towards the right direction. This is measured using open-ended questions before and after the experiment. A change in attitude is also identified by the problem-solving pattern of each participant. The possible scenarios for the problem used in the experiment can be categorized into five categories as shown in Table 2 (Category 5 is a subgroup of Category 4 and includes the scenarios that are deemed to solve the problem). The types of scenarios a participant has attempted over time are plotted sequentially in a graph. This graph provides a visual measure of the change in each participant's attitude. 
In order to design and run successfully a laboratory experiment, however, careful thought and consideration must also be given to the participants, the procedure and the experimental materials (Größler 2004). These are next explained in the following sub-sections.

Table 2: Possible scenarios for the problem used in the experiment can be separated into 5 categories.

\begin{tabular}{|c|l|}
\hline Scenario Category & \multicolumn{1}{c|}{ Description } \\
\hline $\mathbf{1}$ & Operators $\geq$ Doctors + Nurses \\
\hline $\mathbf{2}$ & Operators < Doctors + Nurses \\
\hline $\mathbf{3}$ & A system with no Experts (i.e. No Doctors or/and Nurses) \\
\hline $\mathbf{4}$ & A system with only Experts (i.e. No Operators) \\
\hline $\mathbf{5}$ & $\begin{array}{l}\text { A system with only 5 Doctors OR a system with 5 Nurses and } \\
\text { up to 2 Doctors }\end{array}$ \\
\hline
\end{tabular}

\subsection{Participants}

In order to carry out the full study we use undergraduate students, who volunteer to participate in the study against a small monetary reward. Based on a previous experimental study by Bakken, Gould and Kim (1992), the use of students for this experimental study is considered to be suitable for the observation of insight generation. This study showed that, in certain cases, students' problem solving approaches may be superior to managers. In particular, in this study managers underperformed students because their prior knowledge and experience prevent them from taking risks and freely experimenting with a simulation model.

For the two experimental conditions fifty first- and second-year undergraduate students, who take business modules but no simulation at Loughborough University, are randomly assigned into each group. 25 for each condition. The control group includes twenty five second- and third-year undergraduate students who take simulation modules at Warwick University. Including students who are familiar with simulation in the control group should not affect the results of the study as they are expected to solve the problem using analytical methods instead of simulation. To ensure a representative and a satisfactory sample size, students are paid a fee for their time (Abeler and Nosenzo 2013). An additional small monetary reward, linked to the achievement of the goal of the task, is given to all participants that provide valid solutions (Bonner and Sprinkle 2002).

A pilot study with 11 participants is also carried out in order to test the design of the experiments and the study materials. All participants who were involved in the pilot study were in the age range of $25-30$ years old and chosen on a voluntary basis. In the current paper, we provide the preliminary results of the pilot study (section 4), while the results of the complete study will be presented in a future study.

\subsection{Procedure}

The procedure followed during the experiment for all three conditions is illustrated in Figure 1. All participants are invited to attend one session depending on the treatment they are allocated to. The two experimental sessions are run in parallel (the same date and time). One researcher and one invigilator are assigned for each group. The former leads the session, following a structured pre-set script, and the latter makes sure that participants work individually and in silence.

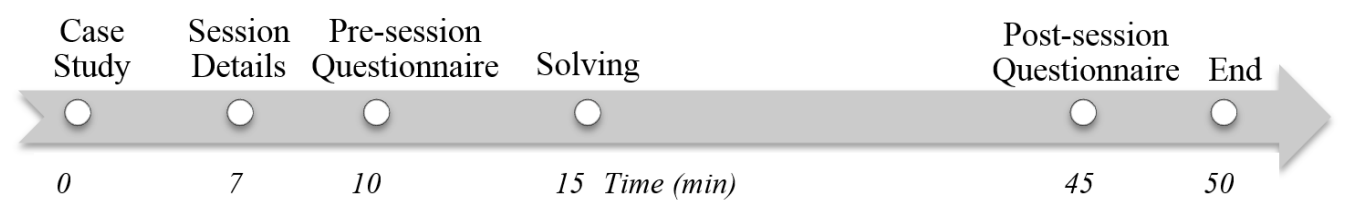

Figure 1: The procedure followed by participants in the control and experimental conditions. 
Initially, the participants read the case study (section 3.5.1). Then they are instructed to read information about the condition they are assigned to and the process of the session. At this stage, participants in the experimental conditions are also instructed to load a simulation model designed using the SIMUL8 software (2013). After reading the session details, participants are given a pre-session questionnaire to complete, consisting of one open-ended question asking their opinion about the NHS111 problem.

After all participants complete the questionnaire, they are provided with written instructions about how to approach the problem. The instructions differ subject to the condition they are assigned to. In particular, participants in condition one are instructed to use the model, by setting up scenarios and then watching the animated view of NHS111's operations in the model. They can use three different speed levels according to their preferences. At the end of a run, the performance (i.e. total cost and mean time in system) of each scenario is provided on screen which can be compared against the targets. Participants in condition two are similarly instructed to use the model like participants in condition one, with the difference that the animation is turned off and they use mainly the statistical results for each scenario such as time in the system, call waiting times, rates of abandoned calls and overestimated referrals. Participants in the control group are instructed to set up scenarios by hand and to then apply their analytical skills (calculators are permitted) to solve the problem.

All participants are given 30 minutes to solve the problem. They are also informed that there is no limitation in the number of scenarios they can run. At the end of the session, participants are asked to submit their best scenario and a short explanation why they think their scenario solves the problem. To ensure that individuals do not influence other participants' thinking, they are instructed to ask questions in writing (an online platform is setup for participants in the experimental conditions).

\subsection{Materials}

The main materials used for the laboratory experiment are a case study and a simulation model. These are next briefly explained.

\subsubsection{Case Study}

The case study used for the experiment is based around a real-life problem, that of the UK's NHS111 service. In the UK's National Health System (NHS) a new telephone service for non-emergency health care has been introduced, called the NHS111 service. The service is largely manned by operators (i.e. low-wage staff, with no medical experience), who are supported by clinical advisors (i.e. high-wage staff, with medical experience), to triage telephone calls and direct people to the right urgent care service first time. When this service was first launched, it failed to cope with patient demand. However, a service manned by low-cost staff with no medical experience is expected to lead to high operating costs (Griffiths, Williams, and Wood 2013).

In our case study, we refer to a fictional local NHS111 service. In particular, the case study explains the problem situation including information about the structure and the types of staff (i.e. operators, nurses and doctors) available in the service; the issues of abandoned calls and overestimated referrals; and the current poor performance in the evening shift of NHS111. The task requires participants to determine the appropriate number of staff (i.e. up to 10 operators, up to 5 nurses and up to 5 doctors) on the evening shift ensuring that the total cost for that shift does not exceed the budget of $£ 2200$ and that a triage is completed on average within 12 minutes. Although, one may initially think that the NHS111 problem may be solved by introducing sufficient call-handling capacity, this is not the case if the following additional information is considered:

- Operators, who are not professionals, usually overestimate the urgency of the call. As a result, an ambulance is dispatched or a caller is directed to A\&E for the wrong reasons. This has an inevitable effect on operating costs. 
- Operators are not able to complete the clinical assessment of more complicated in nature calls. As a result, they need to transfer these calls to clinical advisors. This leads to long waiting times but also to abandoned calls. The latter indirectly affects operating costs because a caller, who abandons a call, usually requires an alternative NHS service (e.g. A\&E or call an ambulance).

Based on the above information, a participant may discover that assigning the burden of triage to operators, albeit being low cost, leads to a more costly and slow service. A participant who realizes this, may have an Aha! moment about how the targets could be achieved by deciding to eliminate the least experienced staff from the service. In other words, participants who have a conscious understanding of the problem may suggest new designs of the NHS111 structure, ideally, by creating scenarios such as the ones in Category 5 (Table 2) which are designed to solve the problem of this exercise.

\subsubsection{Simulation Models}

A simulation model based on the situation explained above is developed using Simul8 Education Edition 2013 (Simul8 2013). The same model is used by the participants of the two experimental conditions with the only difference that participants in condition one can watch only the animation of the model whereas participants in condition two access only the statistical outcomes generated from each simulation run.

\section{PILOT TEST RESULTS}

In the previous section the design of the complete experimental study is explained. At the time of writing this paper, we had only just run the experiments and hence the analysis and results of the complete study were not yet available. For this reason the analysis of the results provided in this section is based on the data obtained from 11 pilot tests conducted prior to carrying out the full experimental study. Participants with no simulation experience were randomly allocated to one of the two experimental conditions, whereas participants with strong analytical skills or/and simulation experience were assigned to the control condition.

To analyze the results of the pilot tests, participants were divided into 'solvers', if they set up a Category 5 scenario and justified their choice, and to 'non-solvers' if they did not run a Category 5 scenario. The number of solvers and non-solvers under each condition is provided in Table 3 . Due to the small sample size of the pilot tests the results provide only some indicative observations about the use of the DES model in generating insights. A brief overview of the observations made follows.

Table 3: Number of solvers and non-solvers in each condition

\begin{tabular}{|c|c|c|c|}
\hline & \multirow{2}{*}{ Control Condition } & \multicolumn{2}{|c|}{ Experimental Conditions } \\
\hline & & 1. Animation & 2. Statistics \\
\hline Solvers & 2 & 2 & 1 \\
\hline Non-solvers & 2 & 2 & 2 \\
\hline $\begin{array}{l}\text { Total Participant } \\
\text { per Condition }\end{array}$ & 4 & 4 & 3 \\
\hline
\end{tabular}

\subsection{Simulation Supports Problem Understanding}

Two out of four non-solvers in the experimental conditions 1 and 2 (i.e. one in each condition), showed evidence of change in their belief about the main problem of NHS111, whereas no change in their beliefs was identified for the two non-solvers in the control group. More specifically, a common misconception about the cause of NHS111 underperformance was considered to be the lack of personnel. This was identified based on the participants' answers to the pre-session questionnaires as well as on participants' initial scenarios, which consisted of assigning more operators than nurses or doctors into the service (i.e. Scenario Category 1, Table 2). However, after running a number of scenarios, all participants in both 
experimental conditions start employing less operators and more nurses and/or doctors (i.e. Scenario Category 2).

This finding could be considered as an indication that the use of simulation supports problem understanding. One could also claim that the change in the type of scenarios considered could be merely a result of trial-and-error or a counter-intuitive decision. However, at the end of the session, even though they did not solve the problem, two out of four (50\%) non-solvers in both experimental conditions 1 and 2 demonstrated a change in their beliefs about the NHS111 problem. For instance, a non-solver in the experimental condition 'Animation', submitted as a solution to the NHS111 problem the scenario ' 1 Operator, 3 Nurses, 3 Doctors' and justified his suggestion as follows: "by using more doctors and fewer operators, overestimated referrals are reduced." In contrast, the non-solvers in the control condition did not show any changes in their initial belief. As a result, at the end of the experiment they still believed that employing more operators will solve the problem.

\subsection{Simulation Supports Divergent Thinking}

Another observation made from the pilots was that participants in the experimental conditions 1 and 2 managed to overcome implicitly posed constraints more frequently than participants in the control group, who were not exposed to simulation. More specifically, all participants started by setting up Category 1 and 2 scenarios (Table 2) as they implicitly assume that all types of staff need to be assigned for the service to operate efficiently. However, after a number of scenario runs, three out of four non-solvers (75\%) in the experimental conditions 1 and 2, created at least one scenario of Category 3 or 4, whereas the non-solvers of the control group did not. Setting up these types of scenarios shows that participants in the two experimental conditions manage to expand their solution space by thinking divergently and therefore suggesting new designs of the NHS111 structure.

One may assume that this may be because solving a problem by hand is a much slower process compared to testing scenarios using a computer-based model. Thus, if more time was given to the control group, more types of scenarios would have been created including scenarios which required divergent thinking. Nevertheless, solvers of the control group required approximately the same amount of time compared to solvers in the experimental condition. Despite the fact that most of the participants in the experimental conditions demonstrated divergent thinking, few succeeded to solve the problem. As a result, they returned to running Category 1 and 2 scenarios straight after having run a Category 4 scenario (Figure 2, left). The above results may indicate that free experimentation with a model might lead to divergent thinking. However, these moments may stem from intuition rather than conscious understanding of the problem (Akinci and Sadler-Smith 2012, Dane and Pratt 2007). Consequently, insights may not emerge.
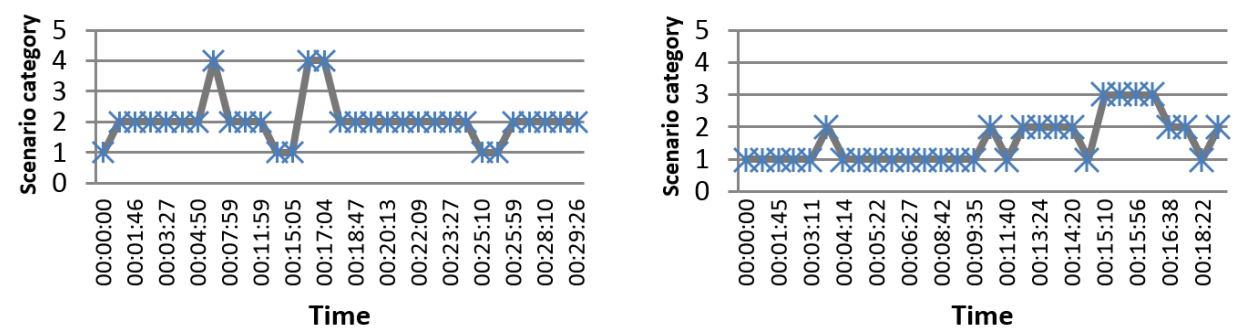

Figure 2. A problem-solving pattern of a participant who showed divergent thinking (left) and of a participant whose behavior was dictated by cognitive biases (right).

\subsection{Cognitive Biases and the Use of Simulation}

Another observation made during the pilots was that the behavior of participants in the experimental conditions 1 and 2 may be dictated by cognitive biases. For instance, running a scenario with no doctors 
(Category 3, Table 2), although it shows that the common implicitly posed constraint of employing all types of staff is overcome, it still shows that the inferences about the NHS111 problem were drawn in an illogical fashion. While two participants in the experimental conditions, who ran a Category 3 scenario, were found to appreciate their deviation in judgment after a few runs and corrected it (Figure 2, right), none of the participants in the control condition considered running scenarios without medical advisors.

This observation could be explained using the theory of the two modes of thinking, System 1 and System 2 (Kahneman 2011). According to this theory, people use their fast mode of thinking (System 1) when they base their decisions on intuition and their slow mode of thinking (System 2) when they use analytical reasoning. Based on participants' exposure to the simulation model or not, one can assume that they tend to activate different systems of thinking. More explicitly, using a model to set up and test scenario performance has the advantage of an analytical-free problem solving approach. As a result, it could be claimed that participants in the experimental conditions solve the problem by making intuitive decisions, by activating System 1. However, making decisions based on intuition encompasses the risk of overestimating benefits and underestimating costs. In the pilot tests, for example, when one uses a simulation model to set up scenarios, the amount of money saved by firing high-wage professionals may be considered erroneously higher than the cost of inadequate triages. On the other hand, the participants in the control group who did not use a model to support decision-making, would need to use their analytical problem-solving skills, hence activate mainly System 2. This has the advantage of rational weighting of gains and losses and hence avoiding conducting inaccurate judgments.

\section{DISCUSSION AND CONCLUSIONS}

This paper presents an overview of an experimental study, part of an ongoing $\mathrm{PhD}$ research, that aims to provide empirical evidence on the role that the simulation model and its features have in insight generation. More specifically, we explore the extent to which features of Visual Interactive Modelling and Simulation, animation or statistical results, support insight generation. A controlled laboratory experiment is employed, using a between groups design. One independent variable is manipulated: the features of the simulation model, forming three conditions. Participants either use the animation or only the statistical results of the model or no model at all to solve the task. In this paper, we present the preliminary results and our observation from 11 pilot tests and not the results of the complete study. Although the results from the pilots should be considered with caution, there is some indication that the use of DES leads to insight generation. The complete experimental study will follow to support our initial observations.

The study has the following limitations that should be considered. First, the results of this study are obtained from using a single task (case study). The type of materials (case study and simulation model) chosen may affect insight generation differently compared to other case studies. Moreover, our study may not provide generalizable results due to our participant base. Students' problem solving skills might differ considerably compared to managers, who, may not succeed in generating insights as frequently as students due to their prior knowledge and experience. Furthermore, it may be the case that in many simulation interventions experimentation with the model is made by groups rather than individuals. This social dimension of the insight generation process has been excluded from this experimental study. However, we believe that this study provides empirical evidence in support of anecdotal claims that DES promotes insight. It contributes towards better understanding of how DES models support understanding and decision-making.

\section{ACKNOWLEDGMENTS}

The authors acknowledge the financial support and advisory input of SIMUL8 Corporation as well as the feedback of dr. Khayat on the case study. Sections of this paper are based on Gogi, A., A. A. Tako and S. Robinson. 2014. "Generating insights: the effectiveness of simulation models in creative problem solving". In Proceedings of the Operational Research Society Simulation Workshop 2014, edited by B.Tjahjono, C. Heavey, S. Onggo, and D-J. van der Zee. Birmingham, UK: The Operational Research Society. 
Gogi, Tako, and Robinson

\section{REFERENCES}

Abeler, J., and D. Nosenzo. 2013. "Self-Selection into Economics Experiments Is Driven by Monetary Rewards." Discussion Papers 7374, Institute for the Study of Labor (IZA), Bonn, Germany.

Ackoff, R. L. 1979. "The Future of Operational Research Is Past." Journal of the Operational Research Society 30 (2): 93-104.

Akinci, C., and E. Sadler-Smith. 2012. "Intuition in Management Research: A Historical Review." International Journal of Management Reviews 14 (1): 104-122.

Bakken, B., J. Gould, and D. Kim. 1992. "Experimentation in Learning Organizations: a Management Flight Simulator Approach.” European Journal of Operational Research 59 (1): 167-182.

Bayer, S., T. Bolt, M. Kapsali, and S. Brailsford. 2010. "The Social Role of Simulation Models." In Proceedings of the $28^{\text {th }}$ International Conference of the System Dynamics Society, edited T.-H. Moon. System Dynamics Society. Seoul, Korea: Korean System Dynamics Society.

Bell, P. C. 1991. "Visual Interactive Modelling: the Past, the Present, and the Prospects." European Journal of Operational Research 54 (3): 274-286.

Bell, P. C., and R. M. O'Keefe. 1987. "Visual Interactive Simulation - History, Recent Developments, and Major issues." Simulation 49 (3): 109-116.

Bonner, S. E., and G. B. Sprinkle. 2002. "The Effects of Monetary Incentives on Effort and Task Performance: Theories, Evidence, and a Framework for Research." Accounting, Organizations and Society 27 (4): 303-345.

Cronin, M. A., C. Gonzalez, and J. D. Sterman. 2009. "Why Don't Well-Educated Adults Understand Accumulation? A Challenge to Researchers, Educators, and Citizens." Organizational Behavior and Human Decision Processes 108 (1): 116-130.

Dane, E., and M. Pratt. 2007. "Exploring Intuition and its Role in Managerial Decision Making." Academy of Management Review 32 (1): 33-54.

Davidson, J. E. 1995. "The Suddenness of Insight." In The Nature of Insight, edited by R. J. Sternberg and J.E. Davidson, 125-155. Cambridge, MA: The MIT Press.

Dobson, G., and R. Shumsky. 2006. "Web-Based Simulations for Teaching Queuing, Little's Law, and Inventory Management." INFORMS Transactions on Education 7 (1): 106-123.

Elder, M. D. 1992. "Visual Interactive Modelling: Some Guidelines for its Implementation and Some Aspects of its Potential Impact on Operational Research." PhD Thesis, Department of Management Science, University of Strathclyde, Edinburgh.

Griffiths, D., J.E. Williams, and R. M. Wood. 2013. "Modelling Activities at a Neurological Rehabilitation Unit." European Journal of Operational Research 226 (2): 301-312

Größler, A. 2004. "Don't Let History Repeat Itself? Methodological Issues Concerning the Use of Simulators in Teaching and Experimentation." System Dynamics Review 20 (3): 263-274.

Kahneman, D. 2011. Thinking, Fast and Slow. New York: Farrar, Straus and Giroux, Inc.

Kounios, J., and M. Beeman. 2009. "The Aha! Moment the Cognitive Neuroscience of Insight." Current Directions in Psychological Science 18 (4): 210-216.

Langley, P. A., and J. D. Morecroft. 2004. "Performance and Learning in a Simulation of Oil Industry Dynamics." European Journal of Operational Research 155 (3): 715-732.

Maier, N. R. F. 1940. "The Behavior Mechanisms Concerned with Problem Solving." Psychological Review 47 (1): 43-58.

Mayer, R. E. 2010. "Problem Solving and Reasoning." In International Encyclopedia of Education, edited by P. Peterson, E. Baker, and B. McGaw, 273-278. 3rd ed. Oxford: Elsevier.

Metcalfe, J., and D. Wiebe. 1987. "Intuition in Insight and Noninsight Problem Solving." Memory \& Cognition 15 (3): 238-246.

Monks, T., S. Robinson, and K. Kotiadis. 2014. "Learning from Discrete-Event Simulation: Exploring the High Involvement Hypothesis." European Journal of Operational Research, forthcoming.

Morecroft, J. D. 1992. "Executive Knowledge, Models and Learning." European Journal of Operational Research 59 (1): 9-27. 
Paul, R. J., and J. Kuljis. 2010. "Problem Solving, Model Solving, or What?.” In Proceedings of the 2010 Winter Simulation Conference, edited by B. Johansson, S. Jain, J. Montoya-Torres, J. Hugan, and E. Yücesan, 353-358. Baltimore, Maryland.

Robinson, S. 2001. "Soft with a Hard Centre: Discrete-event Simulation in Facilitation." Journal of the Operational Research Society 52: 905-915.

Robinson, S. 2005. "Discrete-event Simulation: from the Pioneers to the Present, What Next?." Journal of the Operational Research Society 56: 619-629.

Schooler, J. W., M., Fallshore, and S. M. Fiore. 1995. "Epilogue: Putting Insight into Perspective." In The Nature of Insight, edited by R. J. Sternberg and J.E. Davidson, 559-587. Cambridge, MA: The MIT Press.

SIMUL8 (2013). Simul8 Simulation Software.

Smith, D. 1990. "The Use of Microcomputer-Based Simulation Models in the Teaching of Operations Management." International Journal of Operations \& Production Management 10 (5): 5-14.

Smith, S. M. 1995. "Getting Into and Out of Mental Ruts: a Theory of Fixation, Incubation, and Insight." In The Nature of Insight, edited by R. J. Sternberg and J.E. Davidson, 229-251. Cambridge, MA: The MIT Press.

Sterman, J. D. 1989. "Modeling Managerial Behavior: Misperceptions of Feedback in a Dynamic Decision Making Experiment." Management Science 35 (3): 321-339.

Sterman, J. D. 1994. "Learning In and About Complex Systems." System Dynamics Review, 10 (2-3): 291-330.

Sternberg, R. J. 2009. Cognitive Psychology. 5th Edition, Cengage Learning: Wadsworth.

van der Zee, D., and J Slomp. 2009. "Simulation as a Tool for Gaming and Training in Operations Management - a Case Study.” Journal of Simulation 3 (1): 17-28.

Warren, K., and P. Langley. 1999. "The Effective Communication of System Dynamics to Improve Insight and Learning in Management Education." Journal of the Operational Research Society, 50 (4): 396-404.

Weisberg, R. W. 1995. "Prolegomena to Theories of Insight in Problem Solving: a Taxonomy of Problems." In The Nature of Insight, edited by R. J. Sternberg and J.E. Davidson, 157-196. Cambridge, MA: The MIT Press.

\section{AUTHOR BIOGRAPHIES}

ANASTASIA GOGI is a $\mathrm{PhD}$ student at the School of Business and Economics, Loughborough University. Anastasia holds a BSc in Industrial Management (University of Piraeus, Greece) and an MSc in Management Sciences (University of Southampton, UK). The aim of her current research is to provide empirical evidence on how the use of simulation models support people in generating insights, working closely with SIMUL8 Corporation as the industrial partner. Her email address is a.gogi@lboro.ac.uk.

ANTUELA A. TAKO is a Lecturer in Operations Research at the School of Business and Economics, Loughborough University. She holds a PhD in Simulation from the University of Warwick. Her research interests include the comparison of simulation approaches, facilitated and participative simulation modelling and conceptual modelling. She is an Associate Fellow of the Operational Research Society (AFORS), UK. Home page: www.lboro.ac.uk/departments/sbe/staff/profiles/takoantuela/tako-antuelaanthi.html. Her email address is a.takou@lboro.ac.uk.

STEWART ROBINSON is Professor of Management Science and Associate Dean Research at Loughborough University, School of Business and Economics. His research focuses on the practice of simulation model development and use. Key areas of interest are conceptual modelling, model validation, output analysis and alternative simulation methods (discrete-event, system dynamics and agent based). Professor Robinson is co-founder of the Journal of Simulation and President of the Operational Research Society. Home page: www.stewartrobinson.co.uk. His email address is s.l.robinson@lboro.ac.uk. 